\title{
Use of Just in Time Maintenance of Reinforced Concrete Bridge Structures based on Real Historical Data Deterioration Models
}

\author{
A. Abu-Tair and A. Al Hussain \\ The British University in Dubai, PO Box 345015, Dubai, UAE
}

\begin{abstract}
Concrete is the backbone of any developed economy. Concrete can suffer from a large number of deleterious effects including physical, chemical and biological causes. Large owning bridge structures organizations are facing very serious questions when asking for maintenance budgets. The questions range from needing to justify the need for the work, its urgency, to also have to predict or show the consequences of delayed rehabilitation of a particular structure. There is therefore a need for a probabilistic model that can estimate the range of service lives of bridge populations and also the likelihood of level of deteriorations it can reached for every incremental time interval. A model was developed for such estimation based on statistical data from actual inspection records of a large reinforced concrete bridge portfolio. The method used both deterministic and stochastic methods to predict the service life of a bridge, using these service lives in combination with the just in time (JIT) principle of management would enable maintenance managers to justify the need for action and the budgets needed, to intervene at the optimum time in the life of the structure and that of the deterioration. The paper will report on the model which is based on a large database of deterioration records of concrete bridges covering a period of over 60 years and include data from over 400 bridge structures. The paper will also illustrate how the service life model was developed and how these service lives combined with the JIT can be used to effectively allocate resources and use them to keep a major infrastructure asset moving with little disruption to the transport system and its users.
\end{abstract}

\section{Introduction}

Although concrete is considered a very durable and strong material, there are many factors that can lead to deterioration of RCC. Bridges specially can be borne to failure and deterioration due to the huge moving loads on their decks.

Corrosion is the most common cause of deterioration for bridges because of the severe exposure and excessive environment conditions. Whether the corrosion is due to chemical attack, physical change or internal reaction the corrosion of steel reduces the residual strength of reinforcement. This can happen when strength of reinforcement is decreased due to the loss of steel section, losing the internal bond and decreasing the concrete cross section by cracking and spalling [1]. Chemical reaction is one of the causes of bridges failure and deterioration. These chemical can range from Sulfuric, chlorides, carbonation and Alkali Silica Reaction (ASR). ASR is more common in high humid and high temperature, the reaction occurs internally and develops gel that oppose internal pressure that reduces the concrete stiffness and strength. It is difficult to predict the occurrence of ASR to concrete structures [2]. Other faults which can require repair include: insufficient cover to steel, honeycombing or voids in the concrete, blemishes such as conspicuous or excessive blow-holes which are not structurally significant but are aesthetically displeasing.

\subsection{Just in time maintenance}

JIT maintenance was first developed in Japan particularly by Toyota engineers who are why it is called Toyota Production System. Later it was adopted by United States and Europe to control the production. From concept of JIT in manufacturing construction industry has adapted the concept to improve the quality of construction and reduce money and time.

Construction and manufacturing has a lot of differences of the end product. The on-site production, uniqueness of projects and the complexity is what construction difficult to adapt to just in time production. Lean Project Delivery System into four interconnected phases: project definition, lean design, lean supply, and lean assembly [3]. For large infrastructure maintenance with good service records and inspection regimes, the use of JIT to plan maintenance priorities would be most useful, this would replace the crises management run by many organisation of leaving a structure to deteriorate until there is a serious danger to public or system before action is taken, such work is usually more costly, less effective 
and results in management playing catch up, with large backlog of maintenance work being delayed or cancelled.

\subsection{Bridge model for service life}

Highway bridges are subjected to deterioration due to the environmental attacks; therefore it is necessary to be able to predict the life-expectancy of the bridge. This is done by developing a model for bridge's life, the maintenance and repairs are easier to perform. The advancement in software and computational hardware has enabled a better modelling to the structure and better understanding of their lifetime behaviour.

Research in life-cycle performance prediction and service-life estimation of bridges has not fully caught up with the impressive advances in today's technology. The use of incremental nonlinear finite element analyses (INL-FEA) in the computation of system reliability of bridge structures has emerged in part due to the advances attained in the finite-element (FE). Quadratic response surface (RS) modelling using design of experiments concepts, and Latin hypercube sampling [4].

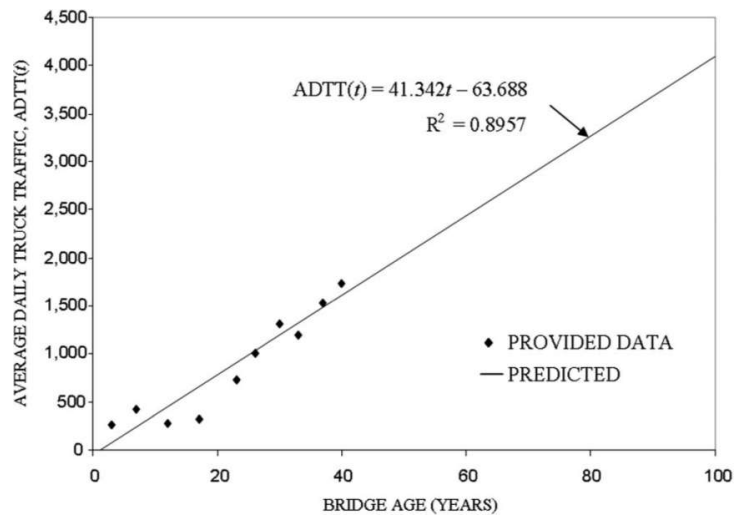

Figure 1: Forecasting ADTT (Average Daily Truck Traffic)

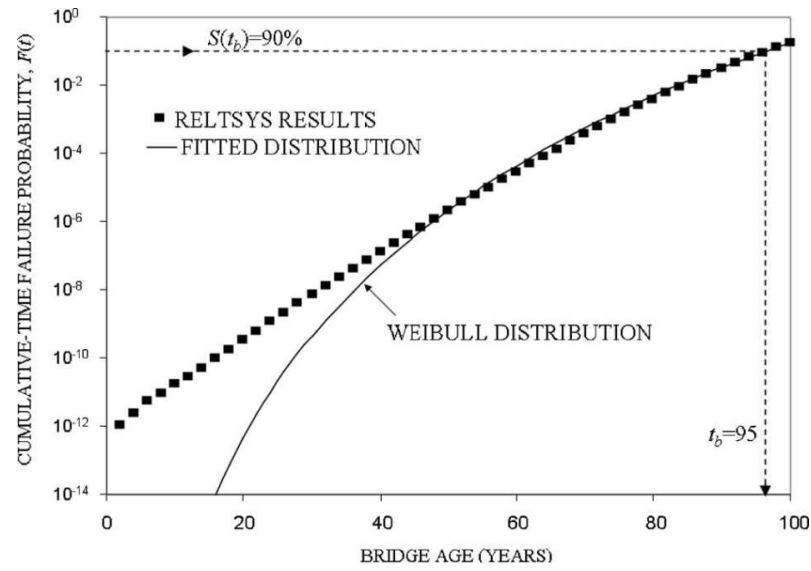

Figure 2: Cumulative-time failure probability of failure of the bridge

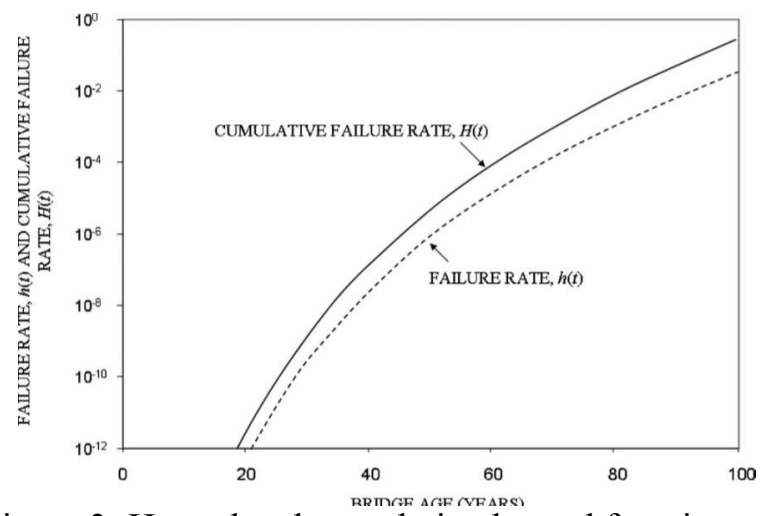

Figure 3: Hazard and cumulative hazard function of the bridge

New method used to predict the life expectancy of concrete bridges using time series variant reliability where load and resistance are considered time dependant. This methods is mainly used to predict the corrosion of steel via time [5].

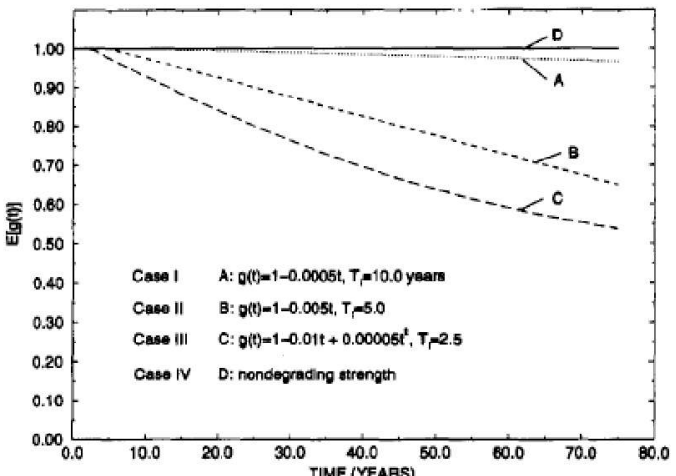

Figure 4: Expected Resistance Degradation versus Time for Cases I-IV

\subsubsection{Stochastic modelling}

The modelling of bridge deterioration has the problem of uncertainty due to the realistic physical process and limited data on the materials, environment and loading characteristics condition exposed. In principle, the methods of structural reliability enable efficient Bayesian updating of any stochastic model with any kind of information Dynamic Bayesian Networks (DBNs) can be applied for the modelling of deterioration [6].

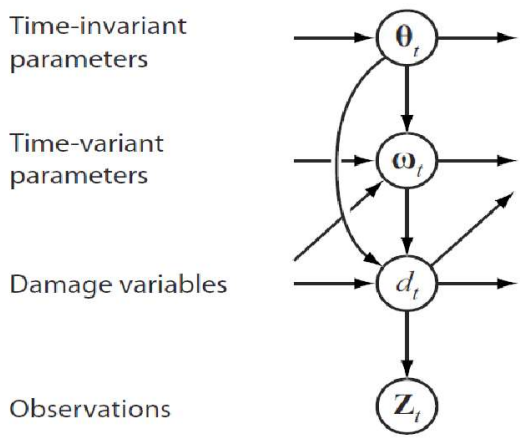

Figure 5 : Dynamic Bayesian Network (DBN) Observation 


\section{Analysis of defects in concrete bridges}

The database contains the defect histories of over 430 concrete bridges in the London area. The life span of many of these bridges begins in the early 1930's with the associated inspection records covering most of this period. A number of these bridges were constructed as long ago as 1889 [7-9]. Figure 6 shows a deteriorated bridge affected by reinforcement corrosion. A sample of the data collected and the fields is given in Table 1. Figure 7 shows the defects recorded from the historical inspection records, over 420 bridge structures were investigated and analysed.

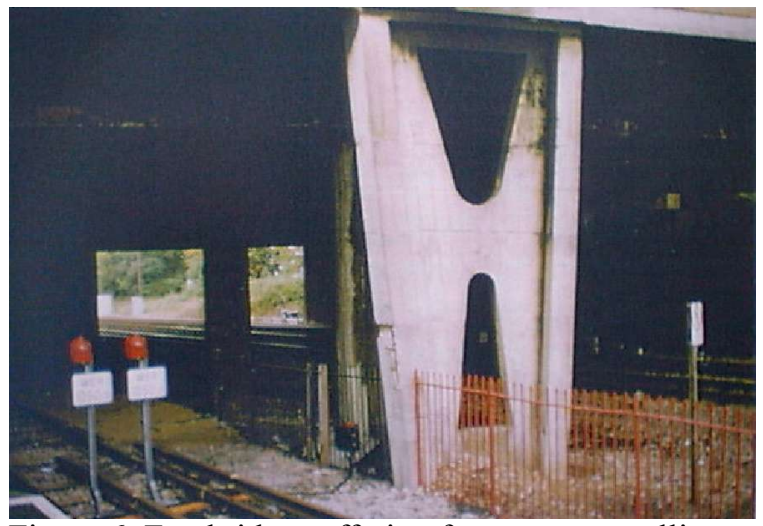

Figure 6: Footbridge suffering from severe spalling caused by corrosion.

\begin{tabular}{|c|c|c|c|c|c|c|c|c|}
\hline Code & Yr built & Inyr & Type & Exp & & Urg & Fault & Age \\
\hline TC001 & 1937 & 1966 & 5 & 2 & & 2 & 7 & 29 \\
TC001 & 1937 & 1970 & 5 & 2 & & 1 & 11 & 33 \\
TC002 & 1937 & 1970 & 5 & 3 & & 1 & 8 & 33 \\
TC002 & 1937 & 1976 & 5 & 3 & & 1 & 9 & 39 \\
TC002 & 1937 & 1982 & 5 & 3 & & 3 & 9 & 45 \\
& & & & & & & & \\
\hline
\end{tabular}

Table 1 : Example of the data contained in the query table.

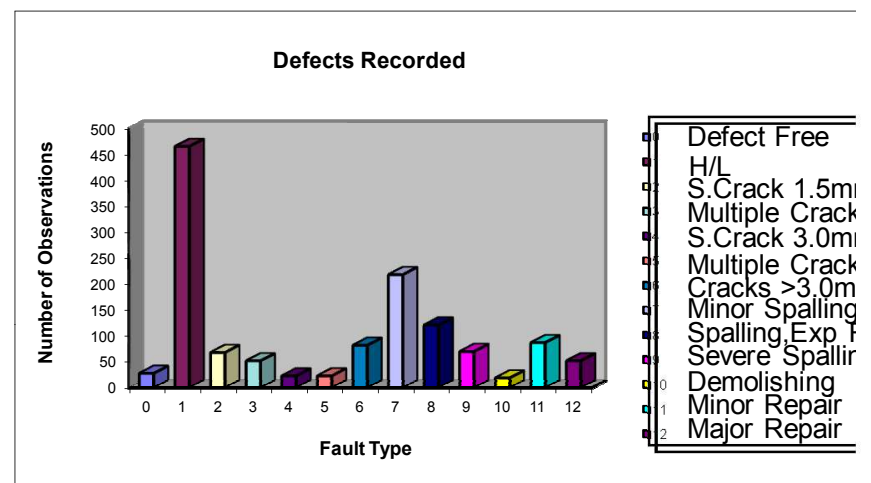

Figure 7 Defects recorded.

\subsection{Extensive Analyses of the Database}

To begin, the data was analysed to determine the types of structure and number of members inspected. A number of graphs were produced to portray this information. These are outlined below.

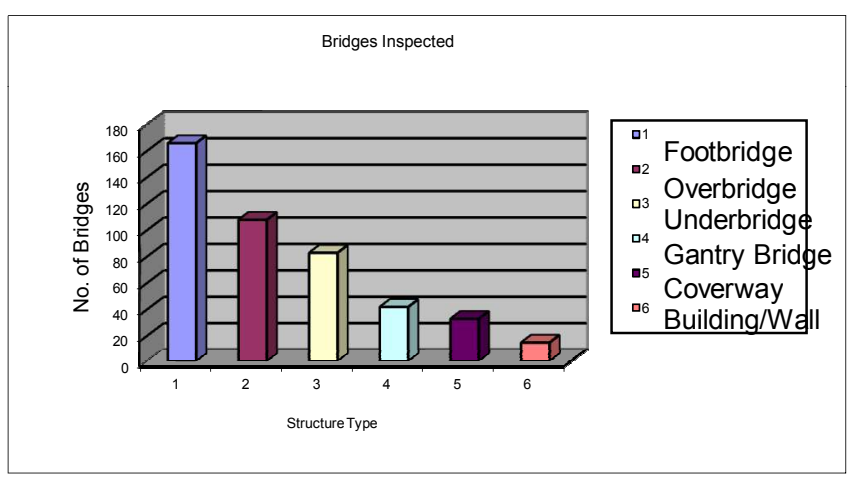

Figure8 Bridges inspected.

- Figure 8 illustrates the range of structures that have been inspected.

- Figure 9 highlights the type of member inspected on each structure and the frequency of that occurrence.

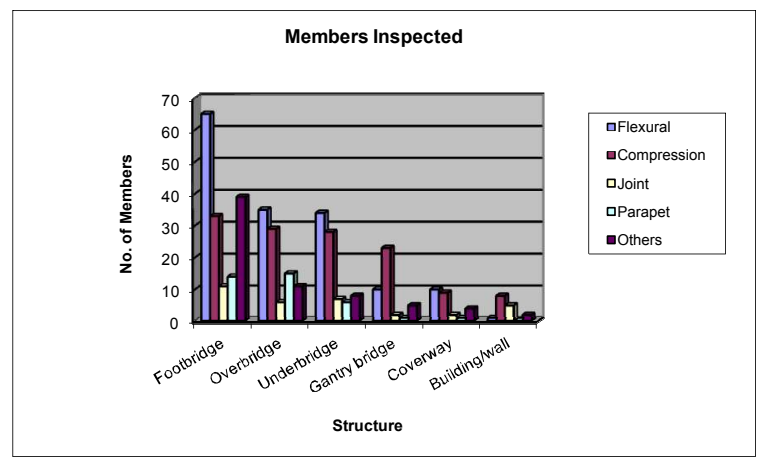

Figure 9: Members inspected.

Perhaps the most significant data recorded during an inspection is the defect of the particular component. During inspections, members are assigned a value according to the most serious defect observed. There are ten possible states, ranging from 0 (defect free) to 9 (severe spalling). Members are assigned the value 10 if they should be demolished, 11 if they require minor repair and 12 if major repair is necessary.

Figure 9 displays the number of each type of defect recorded during the numerous inspections. As this information is recorded for each component the degradation of a particular member can be charted throughout its service life. This information is important in the development of a model predicting the deterioration rate of various components. 
It is possible that some defects may have been incorrectly classified because of the large number of defect types, which increases the influence of subjectivity during inspections. To minimise this ambiguity, defects were sorted into five discrete states:

(i) Defect Free (Defects classified as 0 or 1),

(ii) Minor Cracking (Defects classified as 2, 3 or 4),

(iii) Major Cracking (Defects classified as 5, 6 or 7),

(iv) Spalling (Defects classified as 8 or 9),

(v) Failure (Defects classified as 10, 11 or 12).

These condition states are used throughout the analysis.

\subsection{Example of results}

The tables below gives examples of the service life estimates from the data base for both different structural types and different structural members.

\begin{tabular}{|c|c|c|c|}
\cline { 2 - 4 } \multicolumn{1}{c|}{} & $\begin{array}{c}\text { Mild } \\
\text { Exposure } \\
\text { (Years) }\end{array}$ & $\begin{array}{c}\text { Moderate } \\
\text { Exposure } \\
\text { (Years) }\end{array}$ & $\begin{array}{c}\text { Severe } \\
\text { Exposure } \\
\text { (Years) }\end{array}$ \\
\hline Flexural & 38.0 & $N / A$ & 39.0 \\
Compression & $N / A$ & 41.3 & 44.0 \\
\hline
\end{tabular}

Table 2 Service failure of members.

\begin{tabular}{|c|c|c|}
\cline { 2 - 3 } \multicolumn{1}{c|}{} & $\begin{array}{c}\text { Flexural } \\
\text { (Years) }\end{array}$ & $\begin{array}{c}\text { Compression } \\
\text { (Years) }\end{array}$ \\
\hline Footbridge & 36.7 & 43.3 \\
Overbridge & 38.8 & N/A \\
Underbridge & 36.0 & 46.0 \\
\hline
\end{tabular}

Table 3 Service failure of structures.

\section{Discussion}

The most probable cause of deterioration is most likely to be due to corrosion caused by chloride attack or carbonation. Much of the most severe concentrations of chloride levels from de-icing salt occur where bridge deck joints have leaked, allowing chlorides in water to trickle over the substructure. Too many deck join ts leak and, therefore, abutments and piers become contaminated. Severe corrosion will inevitably result. Spray from passing traffic is also causing chloride contamination of roadside piers and abutments, but the concentrations tend not to be as high as for leakage. Members were analysed according to the structure type they were part of, flexural and compression members followed similar trends of degradation with the former deteriorating faster [7-9].

From the results obtained by the interrogation of the database it became apparent that there was a definite pattern in the way the information changed under certain conditions [7]. It confirmed the belief that, for a given structure or member, the age and subsequent exposure conditions were key factors in determining the deterioration rate of the element. Using these factors it may then be possible to develop a model that could readily predict the deterioration rate of a given concrete structure.

A combination of Service Life Statistical values combined with good budgeting and JIT intervention would optimise the maintenance structure of any infrastructure authority, like highway and railway entities. This would eliminate the need for major unpredictable budget items to manage crises, which occurs when there is a sudden failure. The service life values where available as in Tables 2 and 3 can be used to plan budgets for the maintenance of a complete portfolio of structures such as rail bridges and for a structured mai8ntenance plan that would deliver an efficient use of resources, maintaining the system running and under full control of the managing authority.

\section{References}

1) Tapan, M., \& Aboutaha, R. S. (2008) Strength evaluation of deteriorated RC bridge columns. Journal of Bridge Engineering, 13(3), 226-236. doi:10.1061/(ASCE)10840702(2008)13:3(226)

2) Alnaggar, M.,Cusatis, G., \& Di Luzio, G. (2013).Lattice discrete particle modeling of alkali silica reaction deterioration of concrete structures.Cement and Concrete Composites, 41, 45. doi:10.1016/j.cemconcomp.2013.04.015

3) Ballard, G., \& Howell, G. (2003). Lean project management. Building Research \&

Information, 31(2), 119-133. doi:10.1080/09613210301997

4) Okasha, N. M., \& Frangopol, D. M. (2010). Advanced modeling for efficient computation of life-cycle performance prediction and service-life estimation of bridges. Journal of Computing in Civil Engineering, 24(6), 548-556. doi:10.1061/(ASCE)CP.1943-5487.0000060

5) Straub, D. (2009). Stochastic modeling of deterioration processes through dynamic Bayesian networks. Journal of Engineering Mechanics, 135(10), 1089-1099. doi:10.1061/(ASCE)EM.1943-7889.0000024

6) Enright, M. P \& Frangopol, D. M. (1998) Service-life prediction of deteriorating concrete bridges. Journal of Structural Engineering, 124(3), 309-317. doi:10.1061/(ASCE)0733-9445(1998)124:3(309)

7) Rigden, S. R. et al, Predicting future performance of concrete bridges using long term inspection records, Proceedings of the $5^{\text {th }}$ International Conference on Structural Faults \& Repair, 1993, 43-46.

8) Christer, A. H. et al, Modelling the deterioration and maintenance of concrete structures, presented at the International Conference of Operation Research, 1993. 
9) Rigden, S. R., et al., Service life prediction of concrete bridges, Concrete Repair, Rehabilitation and Protection, 1996, 705-714. 